\title{
Characterization of Esthetic Orthodontic Wires Made from Glass-Fiber-Reinforced Thermoplastic Containing High-Strength, Small-Diameter Glass Fibers
}

\author{
Yasuhiro Tanimoto ${ }^{\mathbb{D}},{ }^{1}$ Toshihiro Inami, ${ }^{2}$ Masaru Yamaguchi, ${ }^{2}$ Kazutaka Kasai, ${ }^{2}$ \\ Norio Hirayama, ${ }^{3}$ and Yoshio Aoki ${ }^{4}$ \\ ${ }^{1}$ Department of Dental Biomaterials, Nihon University School of Dentistry at Matsudo, 2-870-1 Sakaecho Nishi, Matsudo, \\ Chiba 271-8587, Japan \\ ${ }^{2}$ Department of Orthodontics, Nihon University School of Dentistry at Matsudo, 2-870-1 Sakaecho Nishi, Matsudo, \\ Chiba 271-8587, Japan \\ ${ }^{3}$ Department of Mechanical Engineering, College of Industrial Technology, Nihon University, 1-2-1 Izumicho, Narashino, \\ Chiba 275-8575, Japan \\ ${ }^{4}$ Department of Precision Machinery Engineering, College of Science and Technology, Nihon University, 7-24-1 Narashinodai, \\ Funabashi, Chiba 274-8501, Japan
}

Correspondence should be addressed to Yasuhiro Tanimoto; tanimoto.yasuhiro@nihon-u.ac.jp

Received 19 September 2017; Revised 17 November 2017; Accepted 28 November 2017; Published 28 January 2018

Academic Editor: Fabrizio Sarasini

Copyright (c) 2018 Yasuhiro Tanimoto et al. This is an open access article distributed under the Creative Commons Attribution License, which permits unrestricted use, distribution, and reproduction in any medium, provided the original work is properly cited.

In this work, we investigated the properties of a glass-fiber-reinforced thermoplastic (GFRTP) composed of small-diameter $(\phi=5 \mu \mathrm{m})$, high-strength glass (T-glass) fibers and polycarbonate for esthetic orthodontic wires formed using pultrusion. After fabricating such GFRTP round wires, the effects of varying fiber diameter (5 to $13 \mathrm{~mm}$ ) on the mechanical properties, durabilities, and color stabilities were evaluated. The results showed that the mechanical properties of GFRTPs tend to increase with decreasing fiber diameter. Additionally, it was confirmed that the present GFRTP wires containing T-glass fibers have better flexural properties than previously reported GFRTP wires containing E-glass fibers. Meanwhile, thermocycling did not significantly affect the flexural properties of the GFRTP wires. Furthermore, the GFRTP wires showed color changes lower than the acceptable threshold level for color differences on immersion in coffee. From these results obtained in the present work, the GFRTP wires containing high-strength glass fibers have excellent properties for orthodontic applications. Our findings suggest that the GFRTPs might be applied to all phases of orthodontic treatment because their properties can be tuned by changing the fiber properties such as fiber type and diameter.

\section{Introduction}

Orthodontic wires are widely used in orthodontic appliances throughout treatment. These wires are made from metal alloys such as stainless steel (SS), cobalt-chromium-nickel alloy (Co-Cr), $\beta$-titanium alloy ( $\beta$-Ti), and nickel-titanium alloy $(\mathrm{Ni}-\mathrm{Ti})$ [1]. However, one disadvantage of these metallic wires is the opacity of the metal, which deters many patients from undergoing orthodontic treatment. There is therefore a demand for transparent esthetic orthodontic wires. The use of glass-fiber-reinforced thermoplastics (GFRTPs) is one possible solution to this problem; the transparent or translucent appearance of GFRTP arch wires is considered to be especially attractive.

In a previous study, esthetic orthodontic wires were produced by pultrusion of GFRTPs composed of a polycarbonate matrix reinforced with E-glass fibers [2, 3]. Polycarbonate has been widely used in orthodontic appliances such as esthetic brackets and clear retainers [4], and it was used as a matrix of the GFRTP because of its high transparency, low weight, and high heat resistance $[2,5]$. The previous study confirmed that the GFRTP wires are more transparent than conventional metallic wires [2]. Moreover, field emission scanning electron microscopy and scanning 
probe microscopy analysis indicated that the surface roughnesses of the GFRTP wires are smoother than those of the $\beta$-Ti wire [3]. Furthermore, the GFRTP wires had frictional and flexural properties similar to those of the $\mathrm{Ni}-\mathrm{Ti}$ wires $[2,3]$. These findings show that GFRTP wires composed of polycarbonate and E-glass fibers are promising for use in orthodontic appliances.

The properties of GFRTPs can be tuned by changing parameters such as the fiber type, diameter, and volume fraction [6,7]. Materials reinforced with fibers such as carbon, glass, aramid, and boron are used as alternatives to metals in various industries [8]. Glass fibers are transparent and particularly suitable for esthetic dentistry [9]. Different types of glass fibers are available, and E-glass and highstrength glass (known as S-glass in the USA, T-glass in Japan, and R-glass in Europe) fibers are commonly used $[8,9]$. High-strength glass fibers have a tensile strength onethird greater than that of E-glass fibers. These glass fibers are produced by flowing molten glass through holes in a hightemperature alloy bushing; the temperature, and thus the viscosity, is carefully controlled. The average filament diameter ranges from 4.44 to $13.3 \mu \mathrm{m}$ [8]. The mechanical properties of GFRTPs improve with decreasing fiber glass diameter $[6,10]$. However, there are no research reports regarding the fabrication and characterization of the GFRTP orthodontic wires containing high-strength, small-diameter glass fibers.

On the basis of these results, in the present study, GFRTP wires composed of high-strength glass (T-glass) fibers of small diameter $(5 \mu \mathrm{m})$ and polycarbonate were fabricated using a pultrusion method, for use in orthodontic treatment. The effects of the fiber type and diameter on the properties of the GFRTP wires, such as mechanical properties, durabilities, and color stabilities, were evaluated. The hypothesis was that the mechanical properties of the present GFRTP wires containing T-glass fibers would be superior to those of previously reported GFRTP wires containing E-glass fibers.

\section{Materials and Methods}

2.1. Preparation of Materials. GFRTP wires were fabricated using a previously reported pultrusion technique [2]. A polycarbonate (H4000; Mitsubishi Engineering-Plastics Corp., Tokyo, Japan) was used as the thermoplastic matrix. T-glass fiber filaments (Nittobo Co., Fukushima, Japan) were used for unidirectional reinforcement of the polycarbonate matrix. Table 1 shows the mass percentage compositions of E-glass and T-glass fibers [11]. We prepared GFRTP wires with T-glass fibers of three diameters, that is, $13 \mu \mathrm{m}$ (GFRTP-13), $7 \mu \mathrm{m}$ (GFRTP-7), and $5 \mu \mathrm{m}$ (GFRTP-5), and investigated the effects of the fiber diameter on the GFRTP wire properties. The volume fraction of glass fibers in the GFRTPs was $\sim 0.3$. Round GFRTP wires of diameter $0.45 \mathrm{~mm}$ (0.018 inch) and length $36 \mathrm{~cm}$ were cut from the pultruded samples.

2.2. Frictional Tests. The frictional behaviors of the GFRTP wires were investigated using a computer-controlled Instron
TABle 1: Compositions (wt.\%) of E-glass and T-glass.

\begin{tabular}{lcc}
\hline Composition & E-glass & T-glass \\
\hline $\mathrm{SiO}_{2}$ & $52-56$ & $64-66$ \\
$\mathrm{Al}_{2} \mathrm{O}_{3}$ & $12-16$ & $24-26$ \\
$\mathrm{CaO}$ & $20-25$ & - \\
$\mathrm{MgO}$ & & $9-11$ \\
$\mathrm{R}_{2} \mathrm{O}$ & $0-0.8$ & - \\
$\mathrm{B}_{2} \mathrm{O}_{3}$ & $5-10$ & - \\
\hline
\end{tabular}
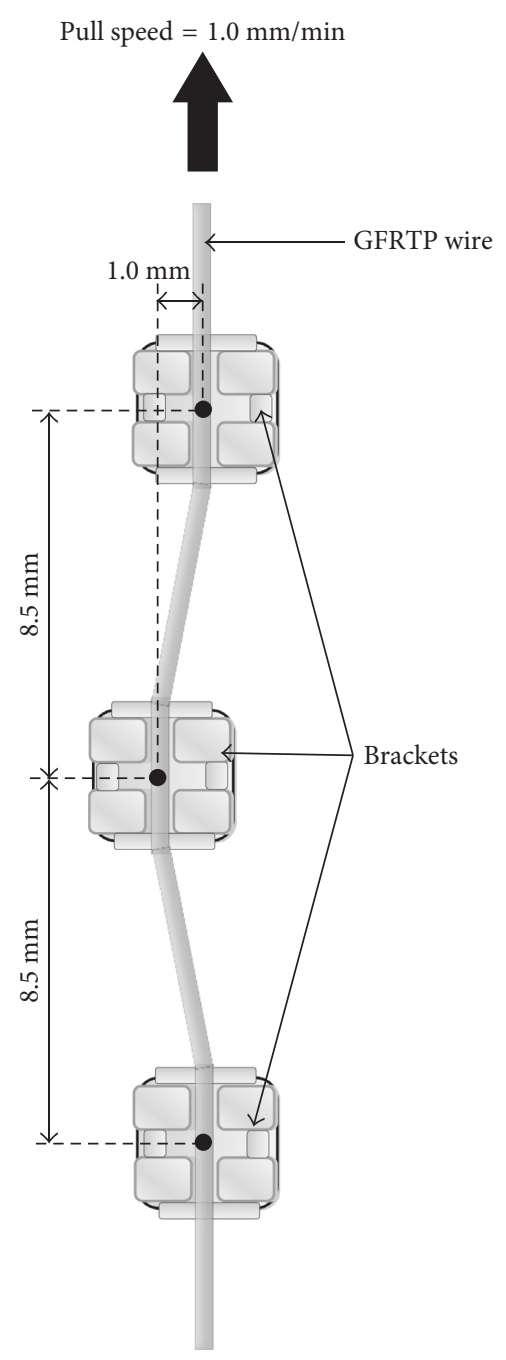

FIGURE 1: Illustration of the frictional testing system.

testing machine (TG-5kN; Minebea, Tokyo, Japan) with jigfixed brackets, as described in a previous report [3]. Before the test, a jig was prepared using a $195 \mathrm{~mm} \times 54 \mathrm{~mm} \times 2.95 \mathrm{~mm}$ acrylic plate, on which three brackets (with a 0.022 inch $\times 0.028$ inch slot) were bonded using cyanoacrylate adhesive. As shown in Figure 1, the positions of the three brackets bonded on the acrylic jig were set. The distance between brackets was $8.5 \mathrm{~mm}$, simulating the upper right lateral incisor, canine, and first premolar brackets. The central bracket was positioned $1.0 \mathrm{~mm}$ more to the left than the other two brackets along a vertical line 
to give three unaligned horizontal brackets. A ceramic bracket (Sincere Brace, Kuraray Noritake Dental Inc., Niigata, Japan) made from zirconia was used as an esthetic bracket. For the friction tests, the wires were cut into segments of length $18 \mathrm{~cm}$. The wires were ligated using elastomeric ligatures (Chain Elastic Ligature Clear, American Orthodontics). Tests were performed using an Instron machine with the cross head speed set at $1 \mathrm{~mm} / \mathrm{min}$; the wire was pulled through the brackets for $2 \mathrm{~min}$, and the maximum loading, that is, the static frictional force, was measured using a load cell of $5 \mathrm{kN}$. A new wire, a bracket, and a fresh ligature were used for each combination and then discarded to eliminate the influence of wear. The frictional test results were reported as the average values for 10 specimens $(n=10)$.

2.3. Three-Point Bending Tests. Three-point bending tests were performed at a constant loading rate of $1 \mathrm{~mm} / \mathrm{min}$ with a span length of $16 \mathrm{~mm}$ using a computer-controlled Instron testing machine, according to the previous study [2]. The GFRTP wires were of length $30 \mathrm{~mm}$. The flexural properties of the GFRTP wires such as the flexural strength and modulus were obtained from three-point bending tests. The experimental values for the GFRTP wires were the averages for 12 specimens $(n=12)$.

2.4. Thermal Cycling. The stability of the mechanical properties of the GFRTP wires was determined by thermocycling between 5 and $55^{\circ} \mathrm{C}$ in deionized water for 600 or 1200 cycles using a thermal cycling machine (Thomas, Tokyo, Japan), according to the previous study [2]. In these thermocycling tests, each GFRTP wire was immersed in one bath for $60 \mathrm{~s}$ and then transferred to another bath within $5 \mathrm{~s}$. After thermocycling, the flexural properties were again evaluated using three-point bending tests and compared with those before thermocycling; the experimental values were the averages for 12 specimens $(n=12)$.

2.5. Weight Change during Immersion. GFRTP wires of length $30 \mathrm{~mm}$ were immersed for 4 weeks in $20 \mathrm{~mL}$ of distilled water (DW) of $\mathrm{pH} 6.0$ at $37^{\circ} \mathrm{C}$ in a Teflon-sealed polystyrene bottle. The DW was replaced every week to expose the samples to a fresh solution. We determined the weight change by weighing the samples before and after immersion, using a precision digital balance (AG285; Mettler-Toledo GmbH, Greifensee, Switzerland). Water sorption and solubility were calculated using the following equations [12]:

$$
\begin{gathered}
\text { Water sorption }(\%)=\frac{\left(w_{2}-w_{3}\right)}{w_{1}} \times 100, \\
\text { Water solubility }(\%)=\frac{\left(w_{1}-w_{3}\right)}{w_{1}} \times 100,
\end{gathered}
$$

where $w_{1}$ is the weight of the sample before immersion, $w_{2}$ is the weight of the sample after immersion, and $w_{3}$ is the weight of the sample which was dried after immersion. The

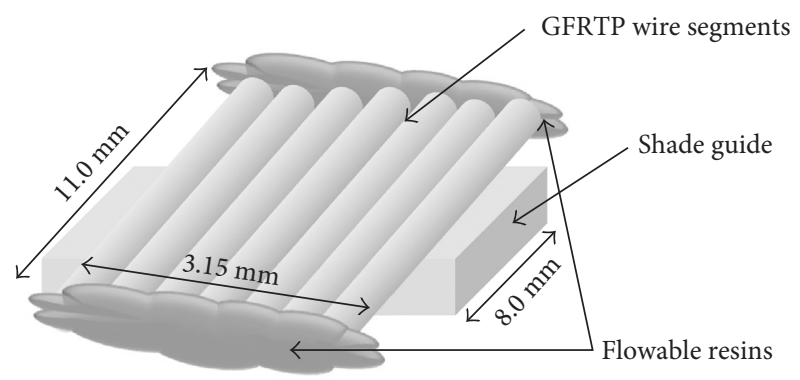

FIgURE 2: Illustration of the GFRTP sample devised for colorimetric measurement.

experimental values were the averages of 5 measurements $(n=5)$.

2.6. Color Stability Evaluation. Direct colorimetric examination of the as-fabricated small-diameter GFRTP wires was impossible; samples with a total width of at least $3 \mathrm{~mm}$ were needed for the color to be determined colorimetrically, as described later. Accordingly, GFRTP samples were prepared by tightly arranging seven wire segments (length $11 \mathrm{~mm}$ and diameter $0.45 \mathrm{~mm}$ ) by fixing both edges with a commercially available flowable resin (Filtek ${ }^{\mathrm{TM}}$ Flow, $3 \mathrm{M}$ ESPE, MN, USA), as shown in Figure 2.

According to the previous study [13], the GFRTP samples were immersed for 4 weeks in $20 \mathrm{~mL}$ of coffee (NESCAFE Excella ${ }^{\circledR}$, Nestlé Japan Ltd., Hyogo, Japan), which was used as a staining solution, in a Teflon-sealed polystyrene bottle at $37^{\circ} \mathrm{C}$; the coffee solution was replaced weekly. After staining, the samples were washed with DW and dried with paper towels. The color changes after immersion for $24 \mathrm{~h}$ and 1,2 , and 4 weeks were determined colorimetrically (ShadeEye NCC, Shofu Inc., Kyoto, Japan) using a shade tab (A3, SOLARE, GC Corp., Tokyo, Japan). This device contains a pulsed xenon lamp as an optical light source and a three-component silicon photocell as the optical sensor. The colorimetric measurements were performed by contacting the measurement tip with the GFRTP sample and using the shade tab as a reference. The values were the averages of 10 samples $(n=10)$, with each sample examined three times.

The color parameters were expressed using the Commission Internationale de l'Eclairage (CIE) $L^{*} a^{*} b^{*}$ color space system, relative to an illuminant standard, D65. In this threedimensional color space, the three axes are $L^{*}, a^{*}$, and $b^{*}$. The $L^{*}$ value is a measure of the lightness of an object and is quantified on a scale such that perfect black has an $L^{*}$ value of 0 and a perfect reflecting diffuser has an $L^{*}$ value of 100 . The $a^{*}$ value is a measure of redness $\left(+a^{*}\right)$ or greenness $\left(-a^{*}\right)$. The $b^{*}$ value is a measure of yellowness $\left(+b^{*}\right)$ or blueness $\left(-b^{*}\right)$.

The difference between the colors $\left(\Delta E^{*}\right)$ before and after immersion was calculated as $[13,14]$

$$
\Delta E^{*}=\left[\left(\Delta L^{*}\right)^{2}+\left(\Delta a^{*}\right)^{2}+\left(\Delta b^{*}\right)^{2}\right]^{1 / 2} .
$$

The $\Delta E^{*}$ values were converted to the National Bureau of Standards (NBS) units using the following equation $[13,15]$ : 


$$
\text { NBS units }=\Delta E^{*} \times 0.92 \text {. }
$$

The values are listed in Table 2 [13].

2.7. Statistical Analysis. The experimental results were evaluated using analysis of variance and tested using Scheffe's multiple comparison test among the means, with $p<0.05$ considered significant.

\section{Results and Discussion}

In the present study, the properties of GFRTP wires containing T-glass fibers of various diameters and polycarbonate for esthetic orthodontic appliances were investigated.

3.1. Frictional Properties. In terms of biomechanics, the frictional properties of orthodontic wires are an important parameter in achieving optimum tooth movement. In particular, the efficiency of tooth movement in the leveling stage can be adversely affected by friction generated between the wire and bracket [16]. Table 3 shows the frictional forces of the GFRTP wires against esthetic brackets made from zirconia. There were significant differences between the frictional forces of GFRTP-5 and GFRTP-13 and between those of GFRTP-5 and GFRTP-7 $(p<0.05)$. Generally, the frictional properties of orthodontic wires are affected by their surface characteristics [3, 17]. The surfaces of all the fabricated GFRTP wires are the same, that is, polycarbonate, because most of the reinforcing glass fibers are embedded in the polycarbonate matrix $[2,3]$. This suggests that the surface properties of GFRTP wires do not cause differences among their frictional properties.

The frictional forces are affected not only by the surface roughness but also by the material's stiffness [3], that is, contact forces between the two surfaces (i.e., the wire and the bracket) during sliding in frictional tests increase with increasing wire's stiffness [17]. In terms of the flexural properties of the GFRTP wires, described later, the flexural modulus tends to increase with decreasing fiber diameter (Table 4). It is therefore thought that the frictional force of GFRTP-5 is significantly higher than that of GFRTP-13 and GFRTP-7 (Table 3).

A comparison with the results of a previous study of currently used metallic wires such as SS and Co-Cr [3] shows that the frictional forces $(3.62-4.73 \mathrm{~N})$ of GFRTP wires containing T-glass fibers of various diameters ( 5 to $13 \mu \mathrm{m}$ ) are lower than those of SS wires $(7.53 \mathrm{~N})$ and $\mathrm{Co}-\mathrm{Cr}$ wires $(7.62 \mathrm{~N})$. Generally, minimizing the friction between the wire and bracket during orthodontic tooth movement is important for optimum orthodontic treatment. GFRTP wires therefore give superior sliding mechanics with low frictional resistance between the wire and bracket during orthodontic treatment.

3.2. Flexural and Durability Properties. The flexural properties of the GFRTP wires before and after thermocycling are
TABLE 2: National Bureau of Standards (NBS) ratings.

\begin{tabular}{lcc}
\hline NBS unit & \multicolumn{2}{c}{ Critical remarks of color differences } \\
\hline $0.0-0.5$ & Trace & Extremely slight change \\
$0.5-1.5$ & Slight & Slight change \\
$1.5-3.0$ & Noticeable & Perceivable \\
$3.0-6.0$ & Appreciable & Marked change \\
$6.0-12.0$ & Much & Extremely marked change \\
12.0 or more & Very much & Change to other color \\
\hline
\end{tabular}

TABLE 3: Frictional forces of GFRTP wires against brackets.

\begin{tabular}{lc}
\hline Sample & Frictional force $(N)$ \\
\hline GFRTP-13 & $3.62 \pm 0.33^{\mathrm{a}}$ \\
GFRTP-7 & $3.86 \pm 0.21^{\mathrm{b}}$ \\
GFRTP-5 & $4.73 \pm 0.28^{\mathrm{a}, \mathrm{b}}$ \\
\hline
\end{tabular}

Mean values with the same superscripts are significantly different from each other $(p<0.05)$.

shown in Table 4. The flexural strengths of GFRTP-13, GFRTP-7, and GFRTP-5 after different numbers of cycles ranged from 913.3 to 958.5 , from 999.2 to 1120.1, and from 1043.5 to $1126.2 \mathrm{MPa}$, respectively. The flexural moduli of GFRTP-13, GFRTP-7, and GFRTP-5 after different numbers of cycles ranged from 34.5 to 35.4 , from 38.4 to 40.5 , and from 38.3 to $42.6 \mathrm{GPa}$, respectively. Before thermocycling, the flexural properties of GFRTP-5 were better than those of GFRTP-13 $(p<0.05)$, that is, the flexural properties of GFRTP wires tended to improve with decreasing fiber diameter. This is because the number of defects in a fiber decreases with decreasing fiber diameter [6]. The trends in the flexural properties of GFRTP wires containing T-glass fibers with changes in the diameter agreed with those previously reported for GFRTP wires containing E-glass fibers [2].

A previous thermocycling study of GFRTP wires with E-glass fibers of diameter $13 \mu \mathrm{m}$ showed that the flexural strength and modulus were $690.3 \mathrm{MPa}$ and $25.4 \mathrm{GPa}$, respectively [2]. The flexural strength and modulus of the GFRTP wire with T-glass fibers of diameter $13 \mu \mathrm{m}$ in the present study were 958.5 $\mathrm{MPa}$ and $35.0 \mathrm{GPa}$, respectively. The flexural properties of GFRTP wires with T-glass fibers are therefore superior to those of GFRTP wires with E-glass fibers. Generally, most of the glass fibers used for reinforcement are of E-glass. In dental applications, there are only a few reports regarding the properties of GFRTPs containing high-strength glass (S-glass) fibers [18]. Such S-glass fibers have a higher strength, modulus, and hardness than E-glass fibers, and their composition (about $65 \% \mathrm{SiO}_{2}$, $25 \% \mathrm{Al}_{2} \mathrm{O}_{3}$, and $10 \% \mathrm{MgO}$ ) is similar to that of T-glass fibers included in the high-strength glass group $[8,9,11,18,19]$. As expected, the properties of the present GFRTP wires containing $\mathrm{T}$-glass fibers are better than those of previously reported GFRTP wires containing E-glass fibers. Our hypothesis was confirmed. In other words, GFRTP wires as tailored orthodontic appliances might be used during all phases of orthodontic treatment, since their properties can 
TABLE 4: Flexural properties of GFRTPs after thermocycling.

\begin{tabular}{|c|c|c|c|c|c|c|}
\hline & \multicolumn{2}{|c|}{0 cycles } & \multicolumn{2}{|c|}{600 cycles } & \multicolumn{2}{|c|}{1200 cycles } \\
\hline & Strength $(\mathrm{MPa})$ & Modulus (GPa) & Strength $(\mathrm{MPa})$ & Modulus (GPa) & Strength $(\mathrm{MPa})$ & Modulus (GPa) \\
\hline GFRTP-13 & $958.5 \pm 137.4^{\mathrm{a}, \mathrm{b}}$ & $35.0 \pm 5.2^{\mathrm{a}}$ & $938.9 \pm 102.2$ & $34.5 \pm 5.6$ & $913.3 \pm 122.1^{\mathrm{a}}$ & $35.4 \pm 5.9$ \\
\hline GFRTP-7 & $1120.1 \pm 197.0^{\mathrm{a}}$ & $40.5 \pm 9.2$ & $1037.0 \pm 123.2$ & $39.7 \pm 6.9$ & $999.2 \pm 56.8$ & $38.4 \pm 6.5$ \\
\hline GFRTP-5 & $1126.2 \pm 92.5^{\mathrm{b}}$ & $42.6 \pm 5.3^{\mathrm{a}}$ & $1043.5 \pm 81.5$ & $40.0 \pm 3.6$ & $1060.4 \pm 102.4^{\mathrm{a}}$ & $38.3 \pm 5.9$ \\
\hline
\end{tabular}

Mean values with the same superscripts are significantly different from each other $(p<0.05)$.

TABLE 5: Water sorption values and solubilities after immersion for 4 weeks.

\begin{tabular}{lcr}
\hline Sample & Water sorption (\%) & Water solubility (\%) \\
\hline GFRTP-13 & $0.67 \pm 0.12$ & $0.07 \pm 0.11$ \\
GFRTP-7 & $0.56 \pm 0.18$ & $0.10 \pm 0.07$ \\
GFRTP-5 & $0.56 \pm 0.20$ & $0.10 \pm 0.10$ \\
\hline
\end{tabular}

No significant differences in both water sorption and water solubility were observed after 4 weeks of immersion $(p>0.05)$.

TABLE 6: Color differences measured in $\Delta E^{*}$ and NBS units after immersion in coffee solution.

\begin{tabular}{|c|c|c|c|c|c|c|c|c|}
\hline & \multicolumn{2}{|c|}{24 hours } & \multicolumn{2}{|c|}{1 week } & \multicolumn{2}{|c|}{2 weeks } & \multicolumn{2}{|c|}{4 weeks } \\
\hline & $\Delta E^{*}$ & NBS units & $\Delta E^{*}$ & NBS units & $\Delta E^{*}$ & NBS units & $\Delta E^{*}$ & NBS units \\
\hline GFRTP-13 & $1.47 \pm 0.52$ & $1.36 \pm 0.48$ & $1.05 \pm 0.46^{\mathrm{a}}$ & $0.97 \pm 0.42^{\mathrm{a}}$ & $1.10 \pm 0.59^{\mathrm{a}}$ & $1.01 \pm 0.54^{\mathrm{a}}$ & $0.83 \pm 0.52^{\mathrm{a}}$ & $0.77 \pm 0.48^{\mathrm{a}}$ \\
\hline GFRTP-7 & $1.34 \pm 0.39$ & $1.23 \pm 0.36$ & $1.11 \pm 0.23^{\mathrm{b}}$ & $1.02 \pm 0.21^{\mathrm{b}}$ & $1.00 \pm 0.36^{\mathrm{b}}$ & $0.92 \pm 0.32^{\mathrm{b}}$ & $0.84 \pm 0.36^{\mathrm{b}}$ & $0.77 \pm 0.33^{\mathrm{b}}$ \\
\hline GFRTP-5 & $1.84 \pm 0.62$ & $1.70 \pm 0.57$ & $2.20 \pm 0.51^{\mathrm{a}, \mathrm{b}}$ & $2.02 \pm 0.47^{\mathrm{a}, \mathrm{b}}$ & $2.07 \pm 0.43^{\mathrm{a}, \mathrm{b}}$ & $1.90 \pm 0.39^{\mathrm{a}, \mathrm{b}}$ & $1.94 \pm 0.48^{\mathrm{a}, \mathrm{b}}$ & $1.79 \pm 0.45^{\mathrm{a}, \mathrm{b}}$ \\
\hline
\end{tabular}

$\Delta E^{*}$ values were converted to NBS units using the following equation: NBS units $=\Delta E^{*} \times 0.92$; mean values with the same superscripts are significantly different from each other $(p<0.05)$; for each GFRTP, there were no significant differences in color change data across all immersion periods $(p>0.05)$.

be tuned by changing the fiber properties such as fiber type and diameter.

In terms of durability, no significant differences in the flexural properties of the GFRTP wires were observed after any number of cycles $(p>0.05)$. This indicates that thermal cycling did not degrade the GFRTP wires. Furthermore, the data in Table 5 show that there were no significant differences among the water sorption abilities and solubilities of the GFRTP wires $(p>0.05)$. This is because polycarbonate, which was used as the matrix resin for the GFRTPs, is a low-sorption material [20]. The results of the durability tests suggest that the mechanical properties of the GFRTP wires would remain stable during the course of orthodontic treatment.

3.3. Color Stability. It is difficult to discern small degrees of color change caused by penetration of colored solutions, using the human eye. Among colored solutions such as coffee, tea, and coke, coffee is the most chromogenic agent [21]. Therefore, applying the same method as used by a previous study [13], the color stability of the GFRTP wires during the 4 weeks of immersion in coffee solution, in terms of two units ( $\Delta E^{*}$ and NBS), was evaluated. Table 6 shows the color differences reported using $\Delta E^{*}$ and NBS units for the GFRTP wires after various immersion periods. The $\Delta E^{*}$ values after different immersion periods for GFRTP-13, GFRTP-7, and GFRTP-5 ranged from 0.83 to 1.47 , from 0.84 to 1.34 , and from 1.84 to 2.20 , respectively. Values of 3.7 $\Delta E^{*}$ or $2.6 \Delta E^{*}$ units have been suggested to be clinically unacceptable [15, 22]. All the experimental values obtained for the GFRTPs in this study were lower than $2.2 \Delta E^{*}$ units, ranging from 0.83 to 2.20 (Table 6). Additionally, there were no significant differences among the measured $\Delta E^{*}$ values for any of the GFRTP wires during different immersion periods $(p>0.05)$.

The degrees of color difference for the GFRTP wires were also assessed in terms of NBS units. The NBS units after different immersion times for GFRTP-13, GFRTP-7, and GFRTP-5 ranged from 0.77 to 1.36 , from 0.77 to 1.23 , and from 1.70 to 2.02, respectively. The data in Table 2 show that the color change values for GFRTP-13 and GFRTP-7 across all immersion periods were lower than 1.5, and only slight color changes were observed in terms of NBS units. The color change values for GFRTP-5 across all immersion periods were lower than 3.0, and noticeable color changes were observed in NBS units. All the GFRTP wires gave color change values lower than the threshold level of 3.0 in NBS units; therefore, the color changes were clinically acceptable [23]. Additionally, there were no significant differences among the color change values for the GFRTP wires across all immersion periods $(p>0.05)$. The results obtained in both $\Delta E^{*}$ and NBS units indicate that discoloration of GFRTP wires will not occur during orthodontic treatment.

\section{Conclusions}

This study investigated the properties of GFRTP wires composed of T-glass fibers and polycarbonate, for use in 
orthodontic treatment. The authors' interpretation of the results is summarized as follows:

(1) The frictional force of GFRTP-5 against zirconia brackets is significantly higher than that of GFRTP13 and GFRTP-7; however, the frictional forces of these GFRTP wires are lower than those previously reported for SS and Co-Cr wires.

(2) The flexural properties of the present GFRTP wires containing T-glass fibers are better than those previously reported for GFRTP wires containing E-glass fibers. Additionally, the flexural properties improve with decreasing fiber diameter, that is, GFRTP-5 has better flexural properties than GFRTP-13 or GFRTP-7.

(3) The results of thermocycling tests show no significant differences in the flexural properties of the GFRTP wires after 600 or 1200 cycles. Moreover, the weight changes for all the GFRTP wires were stable during 4 weeks of immersion in DW at $37^{\circ} \mathrm{C}$.

(4) After immersion in coffee solution for 4 weeks, the color change values for all the GFRTP wires were lower than the threshold levels in $\Delta E^{*}$ and NBS units, that is, the color changes were clinically acceptable. Moreover, there were no significant differences for any of the GFRTP wires during different immersion periods.

Within the limitations of this study, it was confirmed that GFRTP wires containing T-glass fibers have excellent mechanical properties and color stability and are suitable for use in orthodontic treatment. Further investigation of the in vivo behavior of GFRTP wires containing T-glass fibers, such as biomechanics and tissue responses, needs to be performed before they can be used for esthetic orthodontic wires in orthodontic treatment.

\section{Conflicts of Interest}

The authors declare that they have no conflicts of interest.

\section{Acknowledgments}

This work was supported in part by a Nihon University Multidisciplinary Research Grant (2011) and Nihon University Research Grant for Social Implementation (2017).

\section{References}

[1] T. Eliades, "Dental materials in orthodontics," in Orthodontics Current Principles and Techniques, pp. 1023-1037, Elsevier, Philadelphia, PA, USA, 5th edition, 2012.

[2] Y. Tanimoto, T. Inami, M. Yamaguchi, N. Nishiyama, and K. Kasai, "Preparation, mechanical, and in vitro properties of glass fiber-reinforced polycarbonate composites for orthodontic application," Journal of Biomedical Materials Research Part B, vol. 103, no. 4, pp. 743-750, 2015.

[3] T. Inami, Y. Tanimoto, M. Yamaguchi, Y. Shibata, N. Nishiyama, and K. Kasai, "Surface topography, hardness, and frictional properties of GFRP for esthetic orthodontic wires," Journal of Biomedical Materials Research Part B, vol. 104, no. 1, pp. 88-95, 2016.
[4] A. P. Ardeshna, "Clinical evaluation of fiber-reinforcedplastic bonded orthodontic retainers," American Journal of Orthodontics and Dentofacial Orthopedics, vol. 139, no. 6, pp. 761-767, 2011.

[5] K. van Rijswijk and H. E. N. Bersee, "Reactive processing of textile fiber-reinforced thermoplastic composites -An overview," Composites: Part A, vol. 38, no. 3, pp. 666-681, 2007.

[6] J. L. Thomason, "The influence of fibre length, diameter and concentration on the strength and strain to failure of glass fibre-reinforced polyamide 6,6," Composites: Part A, vol. 39, no. 10, pp. 1618-1624, 2008.

[7] Y. Tanimoto, "Dental materials used for metal-free restorations: recent advances and future challenges," Journal of Prosthodontic Research, vol. 59, no. 4, pp. 213-215, 2015.

[8] R. P. Reed and M. Golda, "Cryogenic properties of unidirectional composites," Cryogenics, vol. 34, no. 11, pp. 909-928, 1994.

[9] A. S. Khan, M. T. Azam, M. Khan, S. A. Mian, and I. U. Rehman, "An update on glass fiber dental restorative composites: a systematic review," Materials Science and Engineering C, vol. 47, pp. 26-39, 2015.

[10] V. C. Li and K. Obla, "Effect of fiber diameter variation on properties of cement-based matrix fiber reinforced composites," Composites: Part B, vol. 27, no. 3-4, pp. 275-284, 1996.

[11] F. T. Wallenberger and P. A. Bingham, "High-strength glass fibers and markets," in Fiberglass and Glass Technology, pp. 197-225, Springer, Berlin, Germany, 2010.

[12] R. Z. Alshali, N. A. Salim, J. D. Satterthwaite, and N. Silikas, "Long-term sorption and solubility of bulk-fill and conventional resin-composites in water and artificial saliva," Journal of Dentistry, vol. 43, no. 12, pp. 1511-1518, 2015.

[13] T. Inami, Y. Tanimoto, N. Minami, M. Yamaguchi, and K. Kasai, "Color stability of laboratory glass-fiber-reinforced plastics for esthetic orthodontic wires," Korean Journal of Orthodontics, vol. 45, no. 3, pp. 130-135, 2015.

[14] W. J. O'Brien, "Color and appearance," in Dental Materials and Their Selection, pp. 25-37, Quintessence, Chicago, IL, USA, 4th edition, 2008.

[15] H. L. Filho, L. H. Maia, M. V. Araújo, C. N. Eliast, and A. C. Ruellas, "Colour stability of aesthetic brackets: ceramic and plastic," Australian Orthodontic Journal, vol. 29, no. 1, pp. 13-20, 2013.

[16] M. Maruyama, Y. Namura, T. Tamura, H. Iwai, and N. Shimizu, "Relationship between friction force and orthodontic force at the leveling stage using a coated wire," Journal of Applied Oral Science, vol. 21, no. 6, pp. 554-559, 2013.

[17] V. D’Antò, R. Rongo, G. Ametrano et al., "Evaluation of surface roughness of orthodontic wires by means of atomic force microscopy," Angle Orthodontist, vol. 82, no. 5, pp. 922-928, 2012.

[18] K.-H. Chong and J. Chai, "Strength and mode of failure of unidirectional and bidirectional glass fiber-reinforced composite materials," International Journal of Prosthodontics, vol. 16, no. 2, pp. 161-166, 2003.

[19] X. Li, B. Bhushan, and P. B. McGinnis, "Nanoscale mechanical characterization of glass fibers," Materials Letters, vol. 29, no. 4-6, pp. 215-220, 1996.

[20] I. Hamanaka, M. Iwamoto, L. Lassila, P. Vallittu, H. Shimizu, and Y. Takahashi, "Influence of water sorption on mechanical properties of injection-molded thermoplastic denture base resins," Acta Odontologica Scandinavica, vol. 72, no. 8, pp. 859-865, 2014. 
[21] T. Koksal and I. Dikbas, "Color stability of different denture teeth materials against various staining agents," Dental Materials Journal, vol. 27, no. 1, pp. 139-144, 2008.

[22] R. D. Douglas, T. J. Steinhauer, and A. G. Wee, "Intraoral determination of the tolerance of dentists for perceptibility and acceptability of shade mismatch," Journal of Prosthetic Dentistry, vol. 97, no. 4, pp. 200-208, 2007.

[23] M. Wieckiewicz, V. Opitz, G. Richter, and K. W. Boening, "Physical properties of polyamide-12 versus PMMA denture base material," BioMed Research International, vol. 2014, Article ID 150298, 7 pages, 2014. 


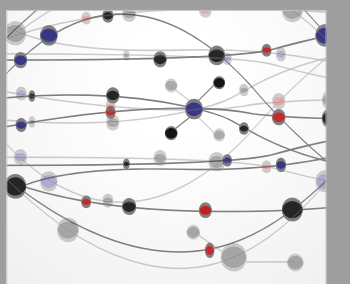

The Scientific World Journal
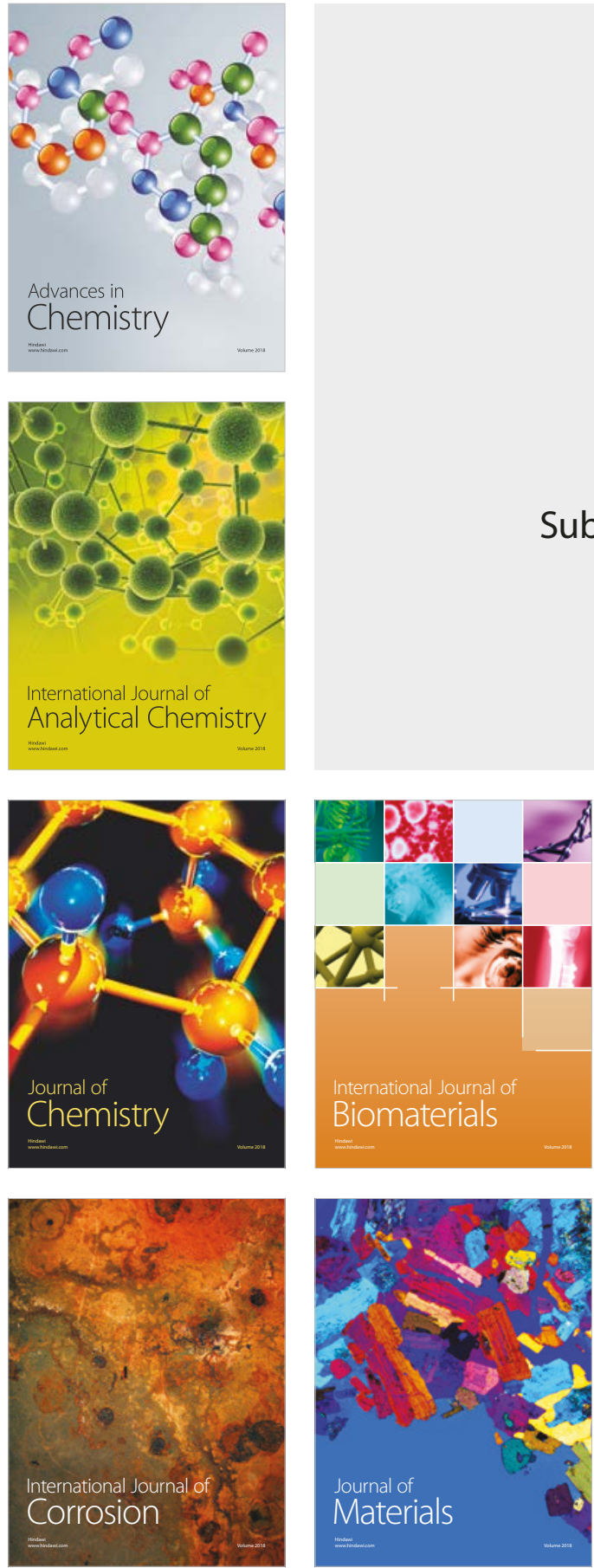

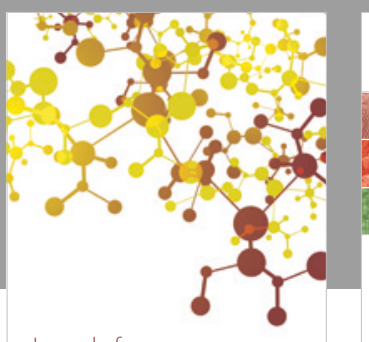

Journal of

Applied Chemistry
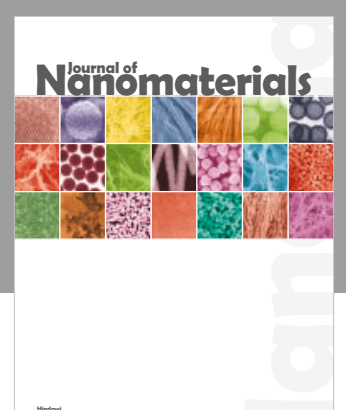

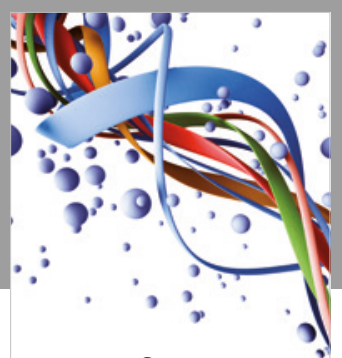

Scientifica

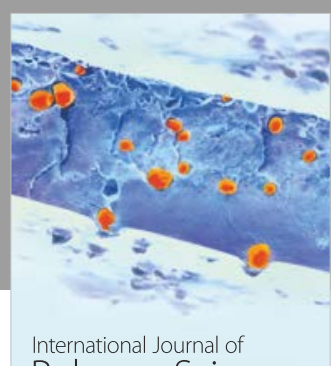

Polymer Science

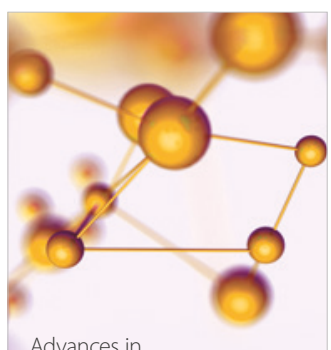

Physical Chemistry
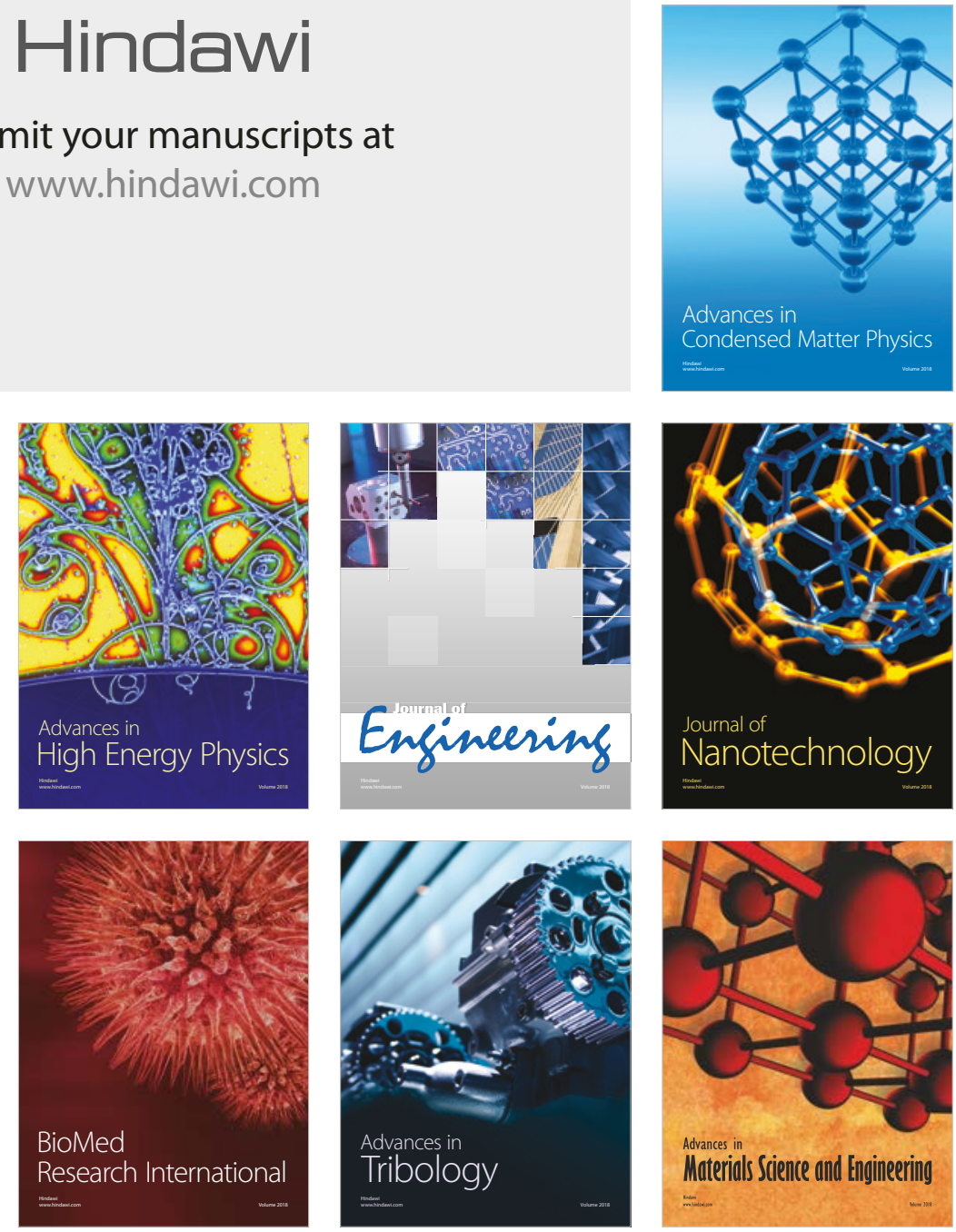